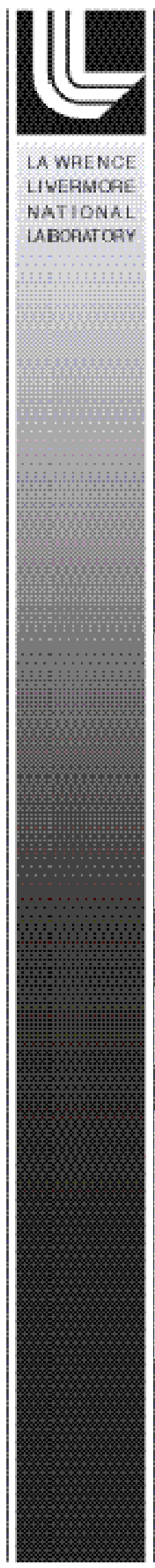

UCRL-JRNL-205039

Extracting growth rates from the non-laminated coralline sponge Astrosclera willeyana using "bomb" radiocarbon

Stewart J. Fallon and Thomas P. Guilderson

6 July 2004

For Limnology and Oceanography: Methods 
This document was prepared as an account of work sponsored by an agency of the United States Government. Neither the United States Government nor the University of California nor any of their employees, makes any warranty, express or implied, or assumes any legal liability or responsibility for the accuracy, completeness, or usefulness of any information, apparatus, product, or process disclosed, or represents that its use would not infringe privately owned rights. Reference herein to any specific commercial product, process, or service by trade name, trademark, manufacturer, or otherwise, does not necessarily constitute or imply its endorsement, recommendation, or favoring by the United States Government or the University of California. The views and opinions of authors expressed herein do not necessarily state or reflect those of the United States Government or the University of California, and shall not be used for advertising or product endorsement purposes. 


\title{
Extracting growth rates from the non-laminated coralline sponge Astrosclera willeyana using "bomb" radiocarbon
}

\author{
Stewart J. Fallon ${ }^{1}$ and Thomas P. Guilderson ${ }^{1,2}$
}

1. Center for Accelerator Mass Spectrometry, Lawrence Livermore National Laboratory, Livermore, California, USA.

2. also at the Department of Ocean Sciences, and Institute of Marine Sciences, University of California, Santa Cruz, California, USA.

\begin{abstract}
Coralline sponges have the potential to fill in gaps in our understanding of subsurface oceanographic variability. However, one disadvantage they have compared to hermatypic reef building coral proxies is that they do not have annual density bands and need to be radiometrically dated for an age determination. To elucidate growth rate variability we have measured radiocarbon in $1 \mathrm{~mm}$ increments from Astrosclera willeyana sponges collected off the Central and Northern Great Barrier Reef (GBR) and from Truk in the Caroline Islands and compared these radiocarbon profiles to independently dated coral radiocarbon records. Growth rates of the GBR sponges average $1.2 \pm 0.3$ and $1.0 \pm 0.3 \mathrm{~mm} \mathrm{yr}^{-1}$, north and central respectively but can vary by a factor of two. The growth rate of the Truk sponge averages $1.2 \pm 0.1 \mathrm{~mm} \mathrm{yr}^{-1}$. These growth rates are significantly faster to those measured for other GBR Astrosclera willeyana sponges $\left(0.2 \mathrm{~mm} \mathrm{yr}^{-1}\right)$ by Calcein staining (Wörheide 1988).
\end{abstract}

Introduction

Coralline sponges are slow growing; long-lived organisms and their calcareous skeletons can provide information on salinity and water temperature variations over their 
life span. Unlike corals, most coralline sponges do not exhibit any annual variations of density or skeletal structure. This makes the generation of accurate time series of environmental parameters difficult. To determine growth rates in coralline sponges, previous studies have traditionally relied on staining (Dunstan and Sacco 1982; Rosenheim et al. 2004; Willenz and Hartman 1985) or radiometric methods, ${ }^{14} \mathrm{C},{ }^{210} \mathrm{~Pb}$ and ${ }^{230} \mathrm{Th} /{ }^{234} \mathrm{U}$ (Benavides and Druffel 1986; Böhm et al. 2000; Fallon et al. 2003; Moore et al. 2000; Wörheide 1998). The majority of paleo-reconstructions take a single linear extension rate extrapolated to the whole organism. In this study we use an extension of a radiometric method where we determine the age and growth rate of a sponge by taking advantage of the atmosphere/surface ocean changes in ${ }^{14} \mathrm{C}$ due to nuclear weapons testing in the 1950 s and 1960 s and then compare our sponge ${ }^{14} \mathrm{C}$ data to surface seawater values. Surface ocean radiocarbon $\left(\square^{14} \mathrm{C}\right)$ is a combination of several processes; lateral mixing of water masses, upwelling of lower ${ }^{14} \mathrm{C}$ water masses and air/sea gas exchange of $\mathrm{CO}_{2}$ that brings higher atmospheric ${ }^{14} \mathrm{CO}_{2}$ to the surface ocean. Atmospheric nuclear weapons testing in the 1950s and 1960s increased the atmospheric $\square^{14} \mathrm{C}$ by $\sim 1000 \%$ o (Levin et al. 1985). The equilibration time between atmosphere and surface seawater is on the order of a decade, suggesting that if all processes are equal (in reality they are not) the surface ocean $\square^{14} \mathrm{C}$ should peak around 1973 (1962/3 being the highest atmospheric $\square^{14} \mathrm{C}$ in the Northern Hemisphere) (Broecker and Peng 1982). The variations of surface water $\square{ }^{14} \mathrm{C}$ over time, the amplitude and the timing of the "bomb" peak provide detailed information about the oceanography and air/sea ${ }^{14} \mathrm{CO}_{2}$ exchange of an area. In general, the "bomb" curve of surface ocean $\square^{14} \mathrm{C}$ has the same general shape in the world's oceans. The surface ocean $\square^{14} \mathrm{C}$ begins to rise in the late 1950 s, peaks in the 1970 s and 
then begins to decrease. In areas with similar radiocarbon surface processes we can take advantage of the "bomb" curve from a well dated coral to provide an age model for nonlaminated coralline sponges like Astrosclera willeyana (Böhm et al. 2002). Here we examine and determine the growth rate of the Indo-Pacific coralline sponge Astrosclera willeyana using high resolution $\square^{14} \mathrm{C}$ measurements compared to precisely dated coral $\square^{14} \mathrm{C}$ records. This enables a detailed examination of growth rate variability (that is crucial to applying these sponges as environmental proxies.

\section{Methods}

The coralline sponges were cut into $5 \mathrm{~mm}$ thick slabs, cleaned in Milli-Q water and dried at $40^{\circ} \mathrm{C}$. Samples were milled sequentially in $1 \mathrm{~mm}$ increments with every sample analyzed. Sponges were milled down the "center" of the slab (Figure 1). ${ }^{14} \mathrm{C}$ sample splits ( $\sim 7 \mathrm{mg})$ were evacuated, heated and acidified in individual chambers with orthophosphoric acid at $90^{\circ} \mathrm{C}$ (Guilderson et al. 1998). The $\mathrm{CO}_{2}$ was purified, trapped and converted to graphite using an iron catalyst following a method similar to that described by Vogel et al., (1987). The graphite targets were analyzed at the Center for Accelerator Mass Spectrometry, Lawrence Livermore National Laboratory. The ${ }^{14} \mathrm{C}$ results are reported as age-corrected $\Delta^{14} \mathrm{C}(\%)$ as defined by Stuiver and Polach (1977) and include $\square^{13} \mathrm{C}$ correction for isotope fractionation, and a blank subtraction based on ${ }^{14} \mathrm{C}$-free calcite. Radiocarbon accuracy and precision is $3.2 \%$ (1口) based on replicate analyses of a homogenous in-house coral standard $(n=89)$. X-Ray and visual analysis of these sponges do not reveal any variations. Two samples were collected from the Great Barrier Reef, Ribbon Reef \#10 at a depth of $21 \mathrm{~m}$ and Myrmidon Reef at a depth of $17 \mathrm{~m}$. 
An additional sample was collected by J. Hooper (Queensland Museum) from Truk in the Caroline Islands at a depth of $25 \mathrm{~m}$.

\section{Results and Discussion}

The Myrmidon sponge is the largest at $50 \mathrm{~mm}$ followed by the Ribbon Reef at 32 $\mathrm{mm}$ and the Truk sponge at $18 \mathrm{~mm}$. The radiocarbon $\left(\square^{14} \mathrm{C}\right)$ results from the three sponges are shown in Figure 2. The Myrmidon sponge $\square^{14} \mathrm{C}$ record displays a rapid rise and peak due to the atmospheric nuclear weapons testing of the 1950s and 1960s, but does not extend to the "pre-bomb" period <1955 (Figure 2). The Ribbon Reef sponge $\square^{14} \mathrm{C}$ captures only part of the "bomb" rise whereas the Truk sample doesn't quite extend to the "bomb" peak (Figure 2).

To determine the growth rates for the Myrmidon and Ribbon Reef sponge we compared the sponge $\square^{14} \mathrm{C}$-distance data to two coral $\square^{14} \mathrm{C}$ records recovered from Heron Island and Abraham Reef (Druffel and Griffin 1995). Figure 3 shows the Myrmidon sponge sample vs. time using the labeled marker points compared to the two coral datasets. The $\square^{14} \mathrm{C}$ coral data was sampled from discrete annual bands cut on the leading edge of the high-density bands and is accurate to about a year (Druffel and Griffin 1995). Using the sample collection date and the marker points, extension rates for the entire time series and between marker points can be calculated (Figure 3). The Myrmidon sponge has an average extension rate of $1.2 \pm 0.3 \mathrm{~mm} \mathrm{yr}^{-1}$ with values ranging from 0.7 to 1.8

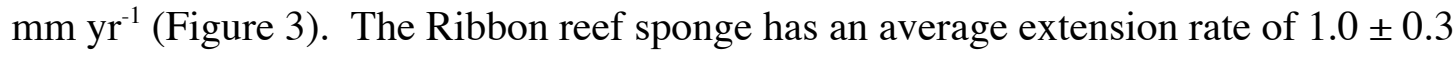
$\mathrm{mm} \mathrm{yr}^{-1}$ with values ranging from 0.7 to $1.5 \mathrm{~mm} \mathrm{yr}^{-1}$ (Figure 4). This data shows that there can be a factor of two in the variability the sponge growth rate indicating that single 
linear extension growth rates are not valid. Both the Myrmidon and Ribbon Reef samples display increasing $\square^{14} \mathrm{C}$ near the base of the sample (Figure 1). Sampling near the base of the sponge may be problematic: multiple time lines may be intersected depending on the "tightness" of the concentric growth lines (see cartoon overlay in Figure 1). We attribute the incongruous $\square^{14} \mathrm{C}$ results at the base to this process. This is not a problem away from the base.

There are no available coral $\square^{14} \mathrm{C}$ datasets available from the Caroline Islands so we chose a high-resolution coral from Nauru (Guilderson et al. 1998) to compare with the Truk sponge sample (Figure 5). This is not as robust of a comparison as the GBR samples but it is good enough to provide gross extension rates for this sample. Using this method we obtain an average extension rate of $1.2 \pm 0.1 \mathrm{~mm} \mathrm{yr}^{-1}$, although this is only based on the collection date and one marker point.

\section{Comparison with other published Astrosclera willeyana growth rates}

The data presented here suggests that the coralline sponge Astrosclera willeyana has a growth (extension) rate of $\sim 1.1 \mathrm{~mm} \mathrm{yr}^{-1}$ but can vary by a factor of two. This is significantly different to the growth rate estimated by Wörheide (1998). Using Calcein$\mathrm{Na}_{2}$ they determined the growth rate over a 1-year period to be $0.23 \mathrm{~mm} \mathrm{yr}^{-1}$ (Wörheide 1998). This also fit with a single $\mathrm{Th} / \mathrm{U}$ and ${ }^{14} \mathrm{C}$ date for a large $25 \mathrm{~cm}$ diameter specimen (Wörheide 1998). Their samples were from nearly the same location as the Ribbon Reef sponge sample used in this study. The only other published growth rates of Astrosclera are from four samples collected in Indonesia and the Solomon Islands by Moore et al., (2000). They used a single $\mathrm{Th} / \mathrm{U}$ date for each sample and the resulting growth rates 
were $0.6,0.65,0.7$ and $0.65 \mathrm{~mm} \mathrm{yr}^{-1}$ (Moore et al. 2000). Due to the large amount of sample needed for the $\mathrm{Th} / \mathrm{U}$ analysis there can be an uncertainty in the growth rate determined by this method, probably $\pm 10-20 \%$. Nonetheless their values are in reasonable agreement with the ones determined in this study. More disturbing however, is the difference between the growth rates measured by staining (Wörheide 1998) and the "bomb" radiocarbon method proposed here. At this point we cannot attribute a cause to the significant differences in growth rate estimates. Some variability can be accounted for if one measures the length (extension) of the transect from different points on the outer edge of the sample. If for instance the sponge is wider than it is tall the apparent growth rates can be different, but not by $6 \mathrm{x}$ as in this case.

\section{Implications for use as an environmental proxy}

If the Astrosclera sponge growth rates can vary from 0.2 to $1.2 \mathrm{~mm} \mathrm{yr}^{-1}$ in individuals collected within $1 \mathrm{Km}$ in the GBR then it would be ill advised to assume a universal or average growth rate. Individual specific growth rate information would be required to place paleo-environmental data on an accurate temporal framework. There also appears to be some variability in the growth rate on annual or longer time scales. To obtain the best and most accurate time series of environmental variables from Astrosclera we recommend a multi-point age model to account for these possible growth rate variations. For samples that are collected near available coral time series, radiocarbon profiles provide a good age constraint for the 1945 to present time period. For samples older than that one can augment the age model with $\mathrm{Th} / \mathrm{U}$ dates. 
Summary

We have used continuous radiocarbon $\left(\square^{14} \mathrm{C}\right)$ profiles in the coralline sponge Astrosclera willeyana to determine precise chronologies and growth rates. Astrosclera willeyana samples in the study have average growth rates of $\sim 1.1 \mathrm{~mm} \mathrm{yr}^{-1}$. This is significantly higher than earlier reports of $0.2 \mathrm{~mm} \mathrm{yr}^{-1}$ by Wörheide (1998) and only slightly higher than the $0.7 \mathrm{~mm} \mathrm{yr}^{-1}$ reported by Moore et al. (2000). We have also found that there is variability in the growth rate on the order of $\sim 0.5 \mathrm{~mm} \mathrm{yr}^{-1}$ depending on the sample. This variability, if unaccounted for, will hinder the efforts to extract environmental information from this genus of coralline sponge.

\section{Acknowledgements}

We would like to thank Gert Wörheide for teaching S.F. to sniff out the Astrosclera and to John Hooper for access to the Queensland Museum sample archive. Thanks also to Paula Zermeño and Dot Kurdyla for help in the graphite lab. This work was performed under the auspices of the U.S. Department of Energy by the University of California, Lawrence Livermore National Laboratory under Contract No. W-7405-Eng-48. Funding for this project was supplied by UC/LLNL LDRD projects 98-ERI-002 and 01-ERI-009 to T.G. 
References 


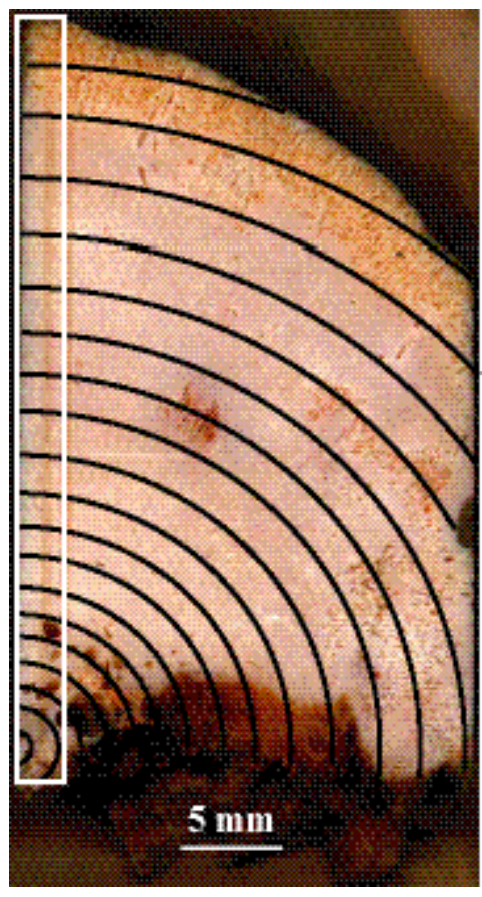

Figure 1. Image of half of a coralline sponge Astrosclera willeyana slab with idealized concentric growth bands overlaid and $\square^{14} \mathrm{C}$ sampling box in white. 


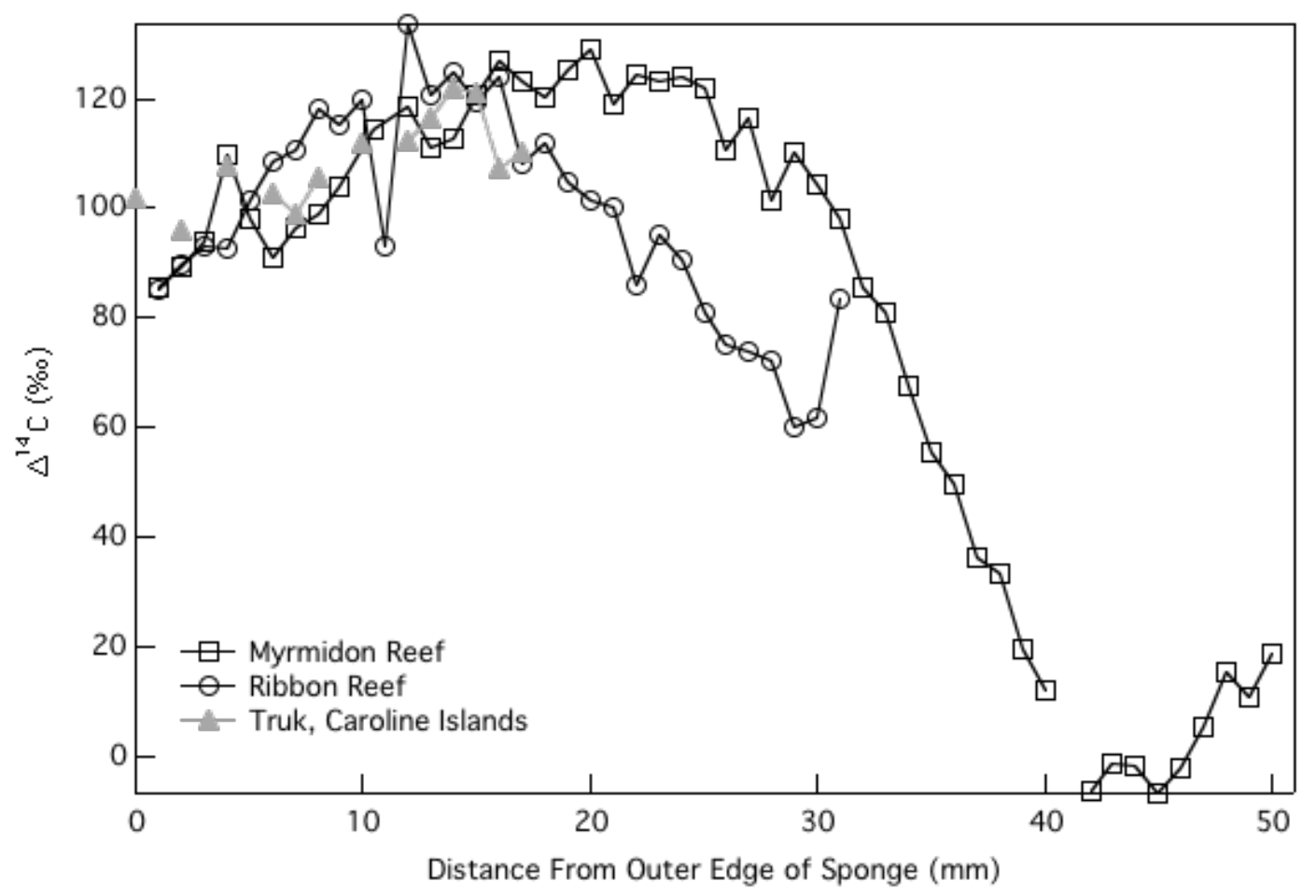

Figure 2. Astrosclera willeyana sample $\square^{14} \mathrm{C}$ vs. distance from the outer edge of the sponge. 


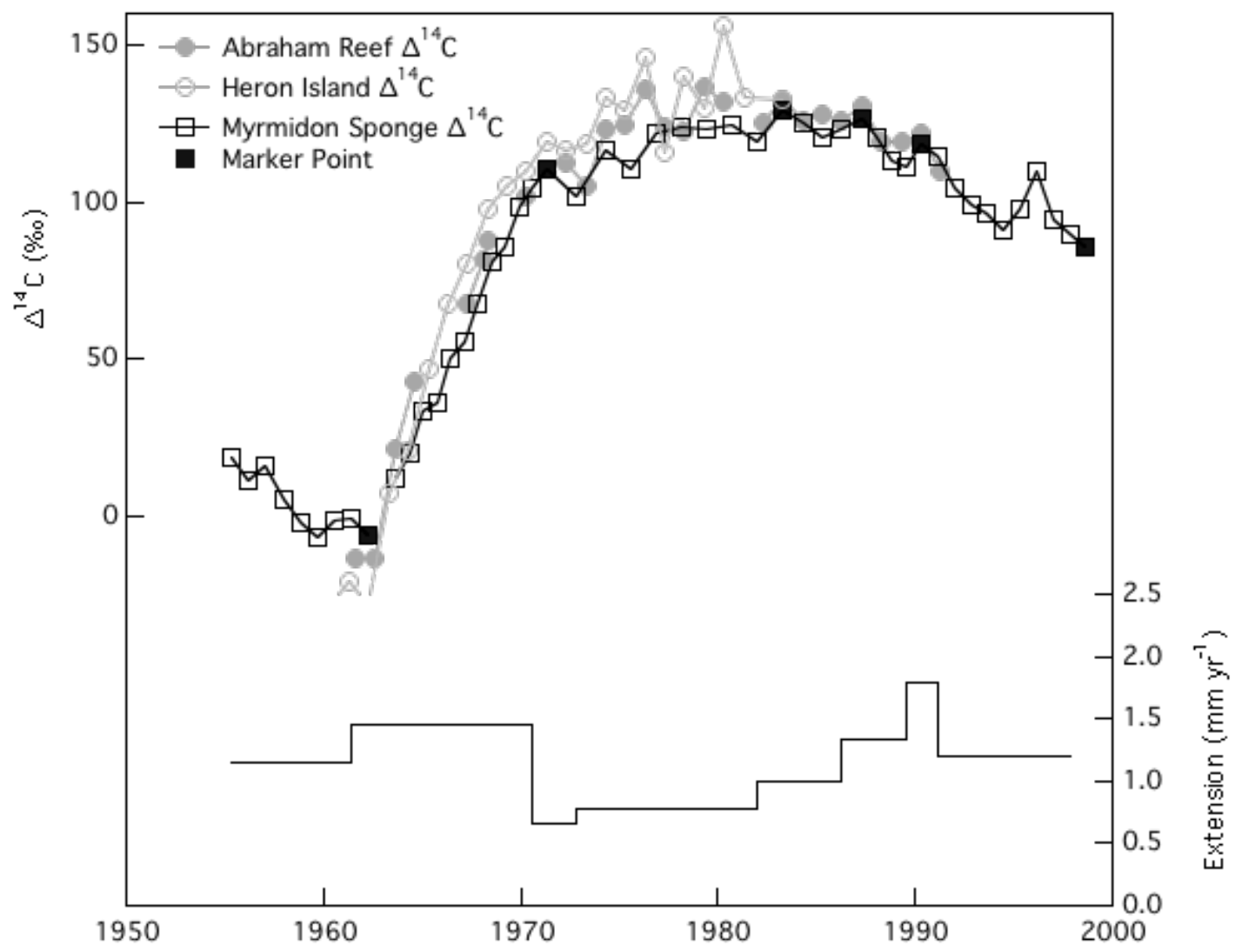

Figure 3. Top panel - Astrosclera willeyana sample from Myrmidon Reef fit to the Heron Island and Abraham Reef corals (Druffel and Griffen 1995). Bottom panel - Growth rate of sponge from fit to GBR corals using marker points. 


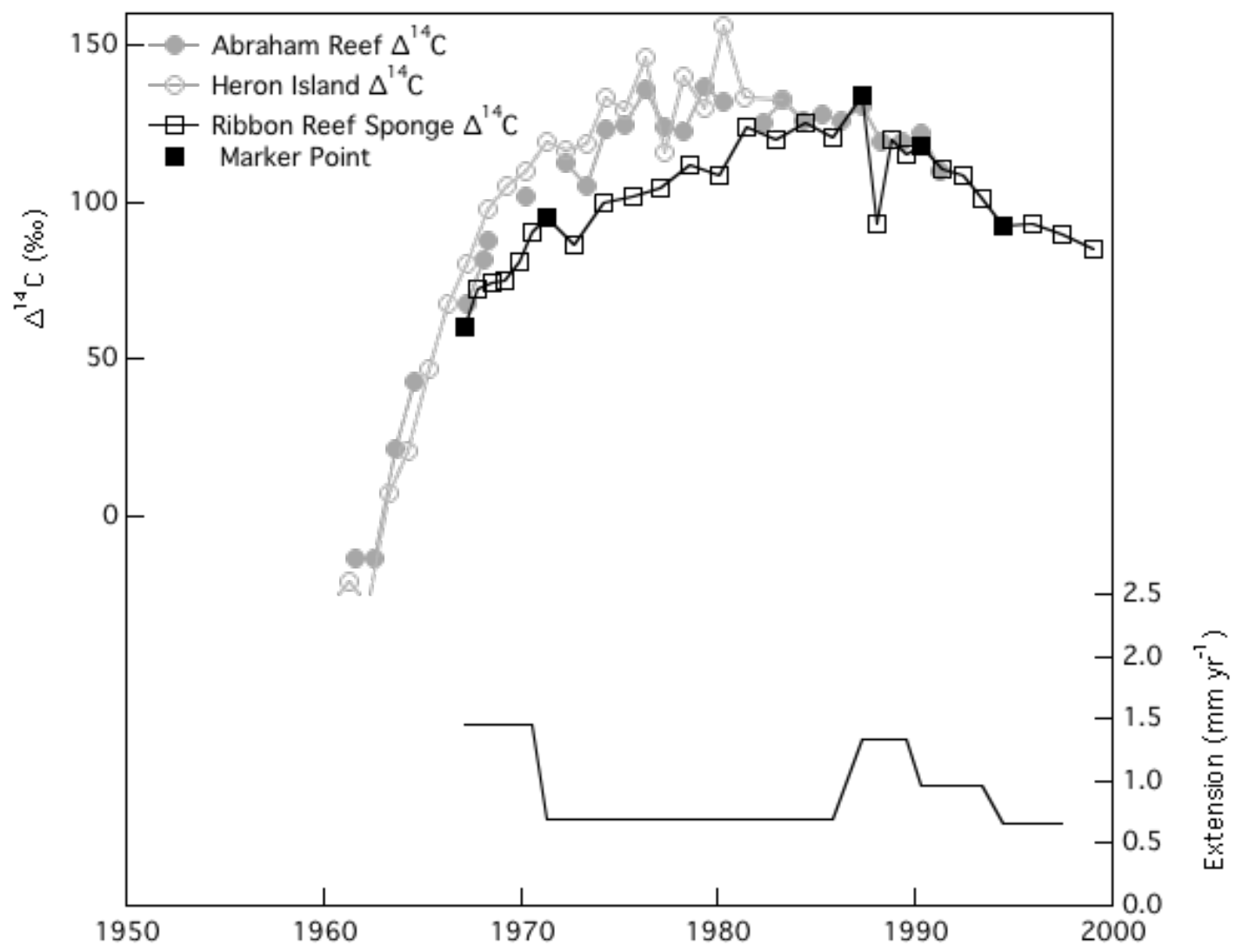

Figure 4. Top panel - Astrosclera willeyana sample from Ribbon Reef\#10 fit to the Heron Island and Abraham Reef corals (Druffel and Griffen 1995). Bottom panel - Growth rate of sponge from fit to GBR corals using marker points. 


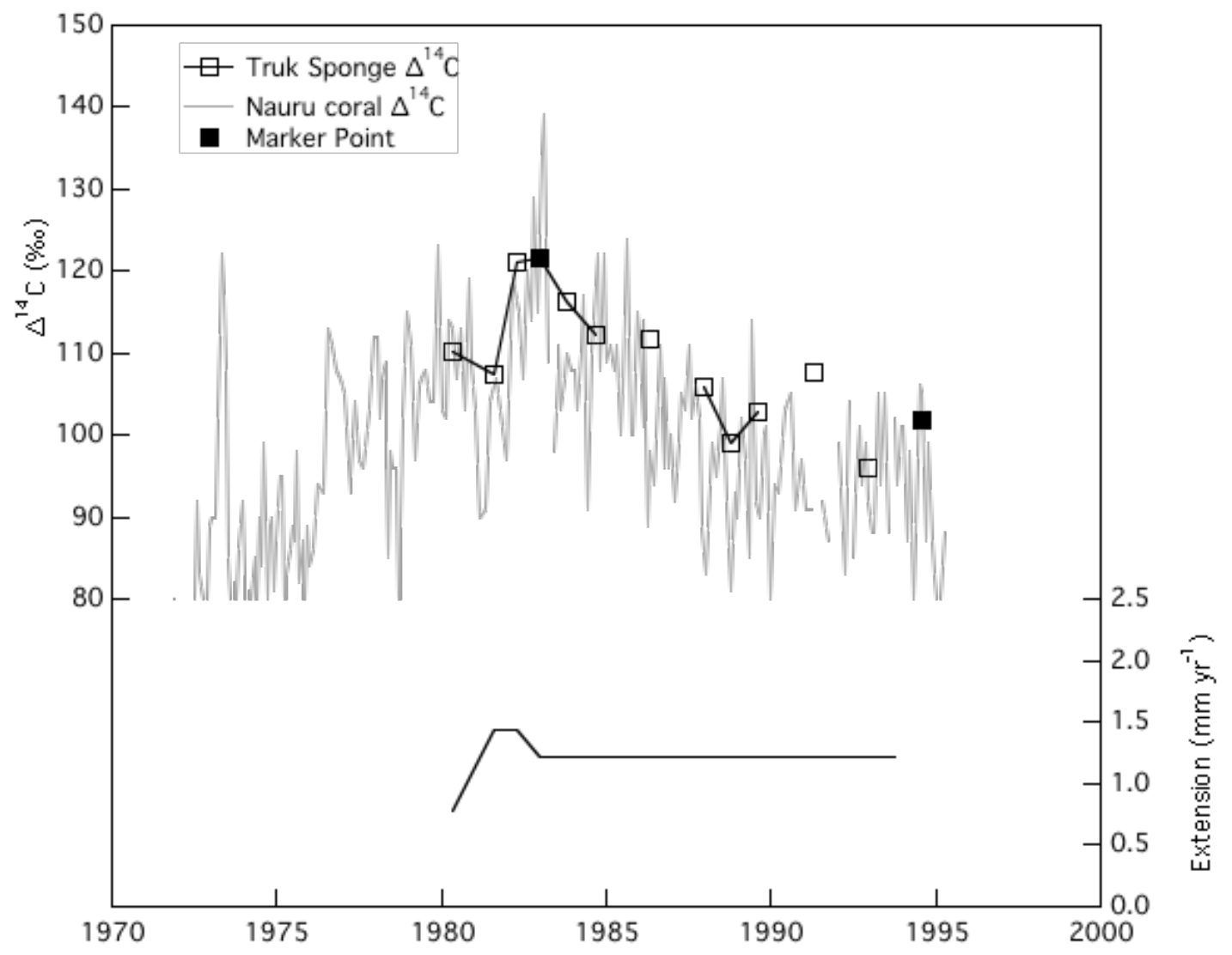

Figure 5. Top panel - Astrosclera willeyana sample from Truk Lagoon, Caroline Islands

fit to a coral from Nauru (Guilderson et al. 1998). Bottom panel - Growth rate of sponge from fit to Nauru coral using marker points.

Benavides, L. M., and E. R. M. Druffel. 1986. Sclerosponge growth rate as determined by ${ }^{210} \mathrm{~Pb}$ and $\square^{14} \mathrm{C}$ chronologies. Coral Reefs 4: 221-224.

Böhm, F., A. Haase-Schramm, A. Eisenhauer, W.-C. Dullo, M. M. Joachimski, H. Lehnert, and J. Reitner. 2002. Evidence for preindustrial variations in the marine surface water carbonate system from coralline sponges. Geochemistry, Geophysics, Geosystems 3: 1-13.

Böhm, F., M. M. Joachimski, W.-C. Dullo, A. Eisenhauer, H. Lehnert, J. Reitner, and G. Wörheide. 2000. Oxygen isotope fractionation in marine aragonite of coralline sponges. Geochim. Cosmochim. Acta 64: 1695-1703.

Broecker, W. S., and T. H. Peng. 1982. Tracers in the Sea. Lamont-Doherty Geological Observatory.

Druffel, E. R. M., and S. Griffin. 1995. Regional variability of surface ocean radiocarbon from Southern Great Barrier Reef corals. Radiocarbon 37: 517-524. 
Dunstan, P., and W. K. Sacco. 1982. The sclerosponges of Chalet Caribe Reef. Discovery 16: 13-17.

Fallon, S. J., T. P. Guilderson, and K. Caldeira. 2003. Carbon isotope constraints on vertical mixing and air-sea CO2 exchange. Geophysical Research Letters 30: 2289-2292.

Guilderson, T. P., D. P. Schrag, M. Kashgarian, and J. Southon. 1998. Radiocarbon variability in the western equatorial Pacific inferred from a high-resolution coral record from Nauru Island. J. Geophys. Res. 103: 24,641-24650.

Levin, I., B. Kromer, H. Schoch-Fischer, M. Bruns, M. Munnich, B. Berdau, J. C. Vogel, and K. O. Munnich. 1985. 25 years of tropospheric 14C observations in Central Europe. Radiocarbon 27: 1-19.

Moore, M. D., C. D. Charles, J. L. Rubenstone, and R. G. Fairbanks. 2000. U/Th-dated sclerosponges from the Indonesian Seaway record subsurface adjustments to west Pacific winds. Paleoceanography 15: 404-416.

Rosenheim, B. E., P. K. Swart, S. R. Thorrold, P. Willenz, L. Berry, and C. Latkoczy. 2004. High-resolution $\mathrm{Sr} / \mathrm{Ca}$ records in sclerosponges calibrated to temperature in situ. Geology 32: 145-148.

Stuiver, M., and H. A. Polach. 1977. Discussion: Reporting of ${ }^{14} \mathrm{C}$ Data. Radiocarbon 19: 355-363.

Vogel, J. S., J. R. Southon, and D. E. Nelson. 1987. Catalyst and binder effects in the use of filamentous graphite for AMS. Nuclear Instruments and Methods in Physics Research B29: 50-56.

Willenz, P., and W. D. Hartman. 1985. Calcification rate of Ceratoporella nicholsoni (Porifera : Sclerospongiae) : An in situ study with calcein, p. 113-118, Fifth International Coral Reef Congress.

Wörheide, G. 1998. The reef cave dwelling ultraconservative coralline demosponge Astrosclera willeyana Lister 19010 from the Indo-Pacific. Facies 38: 1-88. 